\title{
Sex Preference, Religion and Ethnicity Roles in Fertility Among Women of Childbearing Age in Nigeria: Examining the Links Using Zero-Inflated Poisson Regression Model
}

\author{
Ayo Stephen, Adebowale ${ }^{1}$, Soladoye, $\mathrm{Asa}^{2}$, John Olugbenga, $\mathrm{Abe}^{2}$, Funmilola Folasade, Oyinlola ${ }^{2}$ \\ ${ }^{1}$ Department of Epidemiology and Medical Statistics, Faculty of Public Health, College of Medicine, University of \\ Ibadan, Ibadan, Nigeria \\ ${ }^{2}$ Department of Demography and Social Statistics, Faculty of Social Sciences, Obafemi Awolowo University, Ile Ife, \\ Nigeria \\ Correspondence: Ayo S. Adebowale, Department of Epidemiology and Medical Statistics, Oladele Ajose Building, \\ College of Medicine, University of Ibadan, Ibadan, Nigeria. Tel: +234-80-33565210. E-mail: \\ Adehamilt2008@yahoo.com
}

Received: May 2, 2018 Accepted: November 17, 2019 Online Published: November 19, 2019

doi:10.5539/ijsp.v8n6p91 URL: https://doi.org/10.5539/ijsp.v8n6p91

\begin{abstract}
The study aimed at examining the independent and joint influence of three cultural factors; religion, sex preference (SP) and ethnicity on fertility in Nigeria. Cross-sectional population-based cluster design approach was used for the study. The investigated population group was women of reproductive age $(n=19,348)$. Probability of bearing $\geq 5$ children, refined Total Fertility Rate and mean fertility were used to assess fertility. Data were analyzed using demographic and Zero-Inflated Poisson models. Fertility indices were higher among the Hausa/Fulani ethnic group than Igbo and Yoruba and also among Muslim women than Christians. Interaction shows that the probability of bearing at least five children was highest among women who; have no SP, belong to Islamic religious denomination, and of Hausa/Fulani ethnic group. The fertility incident rate ratio (IRR) was higher among women with no SP than women who have SP and also higher among Hausa/Fulani than Yoruba but lower among Christians than Muslims. Fertility differentials persists by ethnicity, religion and SP after controlling for other important variables. Difference exists in fertility among religious, ethnic groups and by SP in Nigeria. Fertility reduction strategies should be intensified in Nigeria, but more attention should be given to Muslims and Hausa/Fulani women.
\end{abstract}

Keywords: fertility, sex preference, religion, ethnicity, Nigeria

\section{Introduction}

Nigeria is the Africa most populous country and among the top ten populous nations worldwide (Population Reference Bureau, 2018). The population projection conducted among countries globally shows that if the current rate of population growth in Nigeria persists, the country's human population will double itself in the next 23 years (Population Reference Bureau, 2016). Fertility is one of the important demographic determinants of accelerated population growth because its control is often hampered by socio-cultural practices (Ramesh, 2010). While most developed countries have transited from the first to the fourth phase of demographic transition, Nigeria is struggling between the first and second stage (Population Reference Bureau, 2016). Although fertility level has reduced in Nigeria in the past few decades, but the current level is high compared to many other countries in sub-Saharan Africa (Population Reference Bureau, 2016). The total fertility rate of 5.5 per woman currently observed in Nigeria and the $2.85 \%$ growth rate have implications for demographic transition, the economic growth and development (Population Reference Bureau, 2016).

Despite high level of fertility in Nigeria, discrepancies in the level of fertility across different population characteristics is one of the most common findings in demographic literature (National Population Commission and ICF International, 2013; Akpa and Ikpotokin, 2012; Chimere-Dan, 1990). Fertility patterns varies in Nigeria due to many factors including cultural norms and these norms are embedded religion and ethnic identity (Akpa and Ikpotokin, 2012; Amoo, 2011). The traditional Nigeria family structure has strong social disposition to large family size and people value children. This is evident in a popular Yoruba adage as for other tribes in Nigeria that says, "He who owns children owns the world." Across the ethnic groups in Nigeria, procreation is desired because by producing children, preferably sons, a woman raises her religious and socioeconomic status in the society (Adebowale et al., 2014; Alo, 2011; Feyisetan and Bankole, 
2002). The role of religion in fertility is often ignored in Nigeria demographic research for political reasons. Islam is often seen as a pronatalist religion which hampers fertility transition in developing countries, but some purely Christian dominated countries in sub-Saharan Africa still have higher fertility than some Muslim dominated countries in the region (PRB, 2016). Thus, the roles of religion, sex preference and ethnicity need further assessment in a high fertility country like Nigeria.

In the past, the ancient demographers have argued that high population should be seen as the wealth of a nation rather than problem as currently witnessed in developing countries today. Malthus in his theory argued that population growth caused by high fertility erodes the welfare and productivity of workers, and thus social policy which fostered greater fertility contributes to 'overpopulation' (Malthus, 1798). High fertility lowers the per capita income growth rate, depletes forest, exhaust ground water, has adverse effect on the distribution of income across the population segment, impede poverty extinction and lowers life expectancy (Schultz, 2005). In a country where these vices are endemic, capitalists become richer while the common man becomes poorer. Thus, high fertility can lead to poverty and poverty also encourages high fertility. Many factors such as; child labor, old age security for parents, child mortality influence fertility. The economic development and female autonomy result in fertility decline because the relative increase in the wage rate of women increases their labor force participation rate which thus leads to fertility decline. Religious, cultural, and social norms put women in a weak bargaining position relative to men in most African societies (Bina, 1997).

As part of measure to reduce rapid population growth in Nigeria, the underline reasons for high fertility must be understood. Instituting more family planning clinics and increasing the disbursement of free contraceptives might be useful but could be an unwise approach to fertility problem in Nigeria if the cultural identities have been neglected. Nigerians view fertility as a legitimate issue for social policy. Factors that have persistently driving high fertility rate in some countries in sub-Saharan Africa are mostly cultural factors. While the relationship between some of these factors and fertility have been extensively explored, very few have examined the interactive influence of religion, sex preference and ethnicity on fertility at national level. Therefore, the primary goal of this study is to assess the independent and joint influence of religion, sex preference and ethnicity on fertility. The study controls for other factors that may have bearing on fertility. The underlying causes of high fertility in Nigeria needs further investigation and exploration in order to understand the circumstances under which public policies might be necessary to reduce fertility in Nigeria, hence this study.

\section{Method}

\section{Study Area}

This study was conducted in Nigeria, sub-Saharan Africa. Nigeria has a population figure of above 180 million and about $24.9 \%$ of the population are women of childbearing age, its population growth rate is $2.6 \%$ per annum and the population doubling time is 23 years (Population Reference Bureau, 2018). Nigeria has many ethnic groups but there are three major ethnic groups (Hausa/Fulani, Igbo and Yoruba) in terms of number (NPC, 2006). These ethnic groups are different in terms of their cultural identities. While the Hausa/Fulani ethnic group are predominantly Muslim, the Igbos and Yorubas are mostly Christians. Sex preference is still practiced in Nigeria but mostly common among the Igbos than any other ethnic groups. While the literacy level is low in Nigeria, there are evidences that the Yorubas are mostly educated than other ethnic groups (NPC, 2006). Harmful demographic practices like child marriage, teenage practices and low contraceptive use are more common among the Hausa/Fulani than Igbo and Yoruba. Also, the Igbos hold more to their cultural identities particularly son preference than any other tribes in Nigeria (Adebowale et al., 2014).

\section{Sample Design and Data Collection Procedure}

The design of the study was cross-sectional and nationally representative in sample selection. The 2013 Nigeria Demographic and Health Survey data was used. During the data collection, a stratified three-stage cluster design consisting of 904 clusters (urban $=372$ and rural $=532$ ) was used. The sample was designed in such a way as to provide data that can be analyzed on fertility and other demographic indices. In this study, we used the section of the data-set that focused on women of reproductive age (15-49 years). Originally, information were obtained from 38948 women, but our study data analysis was based on weighted sample of 19348 women. This is because only women with the complete information on religion, sex-preference and ethnicity were included in the sample. In addition, women who do not belong to any of the three major ethnic groups in Nigeria were excluded. Further excluded were women who belong to other religious denomination that are different from Christianity and Islam which are the two most practiced religious institutions in Nigeria.

\section{Variable Description}

The main independent variables were; religion (Christianity, Islam), sex preference (Yes, No) and ethnicity 
(Fulani/Hausa, Igbo, and Yoruba). The interaction of the three key independent variables used in this study was obtained using the tree diagram (Figure 1).

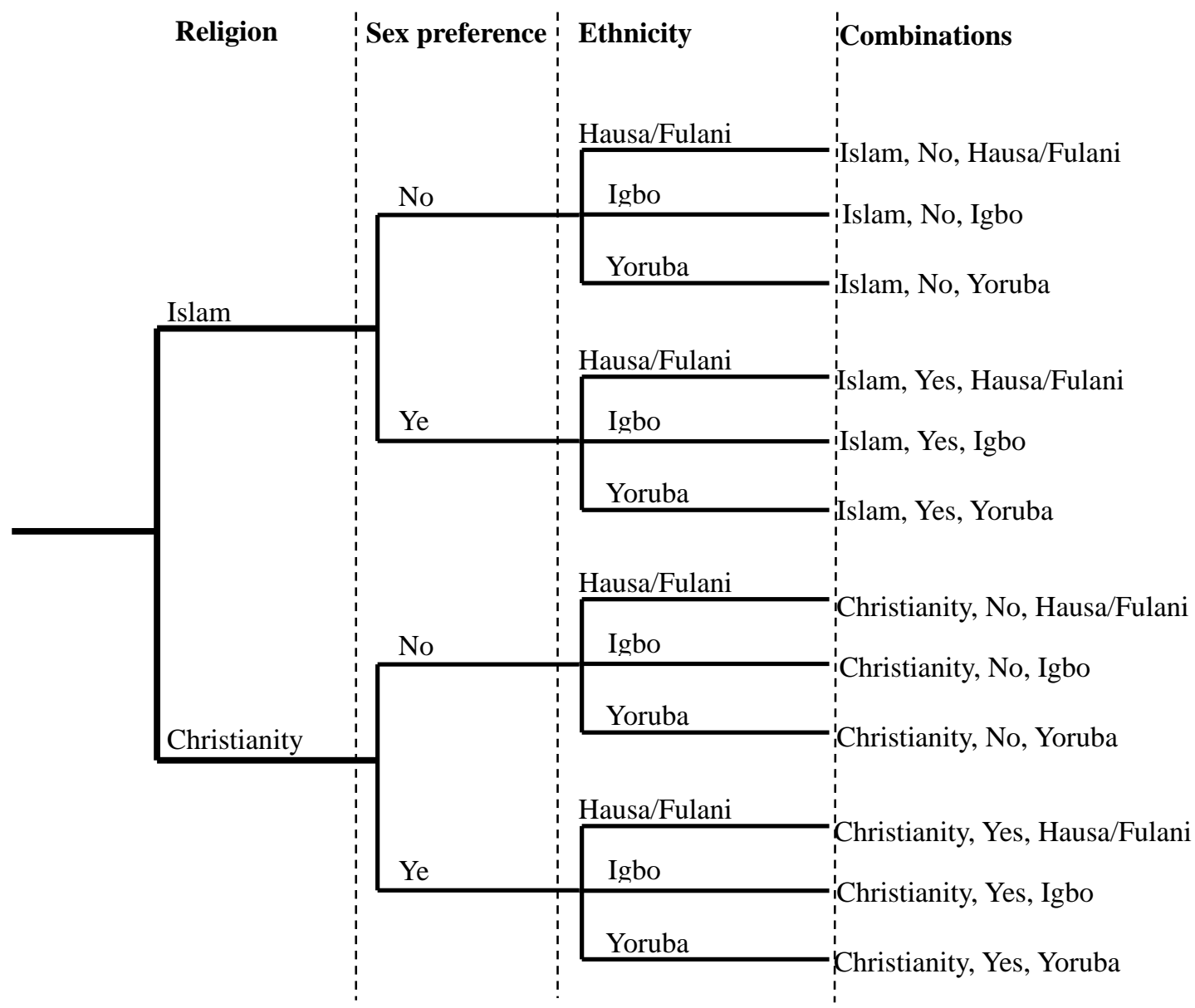

Figure 1. Compositions of the categories of the main independent variables (religion, sex preference, ethnicity Thus, the possible compositions obtained from the interaction are;

\begin{tabular}{llllll}
\hline 1. Islam, No, Hausa/Fulani & (INH) & 7. & Christianity, No, Hausa/Fulani & $(\mathrm{CNH})$ \\
2. & Islam, No, Igbo & $(\mathrm{INI})$ & 8. & Christianity, No, Igbo & $(\mathrm{CNI})$ \\
3. & Islam, No, Yoruba & $(\mathrm{INY})$ & 9. & Christianity, No, Yoruba & $(\mathrm{CNY})$ \\
4. Islam, Yes, Hausa/Fulani & $(\mathrm{IYH})$ & 10. & Christianity, Yes, Hausa/Fulani & $(\mathrm{CYH})$ \\
5. Islam, Yes, Igbo & $(\mathrm{IYI})$ & 11. & Christianity, Yes, Igbo & $(\mathrm{CYI})$ \\
6. Islam, Yes, Yoruba & $(\mathrm{IYY})$ & 12. & Christianity, Yes, Yoruba & $(\mathrm{CYY})$
\end{tabular}

The dependent variable was fertility measured by aggregating full birth history of each of the women who participated in the study.

\section{Method of Analysis}

Three indices were used to describe fertility across the sociodemographic variables. These are; probability of bearing at least 5 children $(\grave{\eta})$, refined Total Fertility Rate (rTFR) and mean fertility $(\mu)$ which was computed using Poisson probability model, $\mathrm{P} / \mathrm{F}$ ratio method and ANOVA respectively. The Chi-square model was used to examine the relationship between the fertility (categorized as: 0, 1-2, 3-4 and $\geq 5$ ) and independent variables. The P/F ratio method was used to estimate rTFR.

The P/F ratio method (Ansley and Trussell, 1974) of fertility estimation method was based on information obtained 
from women aged 15-49 years on children ever born, number of children born during the year preceding the survey, and total number of women in each 5-year age group.

The procedures are;

1. Computation of reported average parities and derivation of preliminary fertility schedule,

2. Calculation of cumulated fertility schedule $\varphi_{i}(\mathrm{i})$ for a period

$$
\varphi_{i}(\mathrm{i})=5 \sum_{\mathrm{j}=0}^{\mathrm{i}} \mathrm{f}(\mathrm{j}) \text {, }
$$

3. Estimation of average parity equivalents $\mathrm{F}(\mathrm{i})$ for a period,

$$
\mathrm{F}(\mathrm{i})=\varphi_{i}(\mathrm{i}-1)+\xi_{1} \mathrm{f}(\mathrm{i})+\xi_{2} \mathrm{f}(\mathrm{i}+1) \text {, }
$$

4. Calculation of a fertility schedule for conventional five-year age group;

$$
\mathrm{f}^{+}(\mathrm{i})=(1-\gamma(\mathrm{i}-1)) \mathrm{f}(\mathrm{i})+\gamma(\mathrm{i}) \mathrm{f}(\mathrm{i}+1)
$$

Where; $\gamma(\mathrm{i})=\mathrm{x}(\mathrm{i})+\mathrm{y}(\mathrm{i}) \mathrm{f}(\mathrm{i}) / \varphi_{i}(7)+\mathrm{z}(\mathrm{i}) \mathrm{f}(\mathrm{i}+1) / \varphi_{i}(7)$,

5. Adjustment of period fertility schedule $\mathrm{f}^{*}(\mathrm{i})=\Omega \mathrm{f}^{+}(\mathrm{i})$,

6. Estimation of refined TFR, $r \mathrm{TFR}=5 \sum_{\mathrm{i}=1}^{7} \mathrm{f}^{*}(\mathrm{i})$.

At the level of multivariate analysis, Zero-Inflated Poisson (ZIP) regression was used.

The starting point for modeling count data like fertility as measured in this study is the use of Poisson distribution. This distribution assumes that the logarithm of its expected value can be modeled by a linear combination of unknown parameters. The Poisson probability distribution is of the form;

$$
\begin{gathered}
P(X=x)=\left\{\mu^{x} \exp (-\mu)\right\} / x !, \quad x=0,1,2, \ldots \\
\therefore \log \{P(X=x)\}=-\mu+x \log _{e} \mu-\log _{e} x !, \quad x=0,1,2, \ldots
\end{gathered}
$$

If $x \in \mathrm{R}^{n}$ is a vector of independent variables, then the model is;

$$
\log (E(Y / x))=\alpha+\beta^{1} x \text {, where } \alpha \in x \text { and } \beta \in \mathrm{R}^{n} .
$$

This can also be written as;

$$
\log (E(Y / x))=\theta^{1} x
$$

where $\mathrm{x}$ is an $(n+1)$ dimensional vector comprising of $n$ independent variables concatenated to a vector of ones and $\theta$ is simply $\alpha$ concatenated to $\beta$. Thus, if Poisson regression model $\theta$ and an input vector $\mathrm{x}$ are known, the predicted mean of the associated Poisson distribution is given by $\mathrm{E}(\mathrm{Y} / \mathrm{x})=\exp \left(\theta^{1} x\right)$. If $Y_{i}$ are independent observations with corresponding values $\mathbf{x}_{i}$ of the predictor variables, then $\boldsymbol{\theta}$ can be estimated by maximum likelihood. The logit model is a transformation of the logistic equation. Logistic is often used to investigate the relationship between a dependent dichotomous variable and set of independent variables. If $y_{i}$ denote the response of woman $i$ with respect to the explanatory variables $x_{1 i}, x_{2 i}, \ldots, x_{k i}$ outcome. Then the logistic regression is;

$$
P\left(Y / x_{1}, x_{2}, \ldots, x_{k}\right)=\frac{e^{\left(\beta_{0}+\beta_{1} x_{1}+\beta_{2} x_{2}+\cdots+\beta_{k} x_{k}\right)}}{1+e^{\left(\beta_{0}+\beta_{1} x_{1}+\beta_{2} x_{2}+\cdots+\beta_{k} x_{k}\right)}}
$$

This logistic distribution function transforms the regression into the interval $(0,1)$. The logit which is the inverse of the sigmoidal logistic function that creates a map of probability values from $[0,1]$ to $(-\infty,+\infty)$ and defined as the logarithm of the odds $(x /(1-x))$ expressed mathematically as;

$$
\begin{gathered}
\operatorname{logit}(x)=\log (x /(1-x)) \\
\operatorname{logit}\left(Y / x_{1}, x_{2}, \ldots, x_{k}\right)=\beta_{0}+\beta_{1} x_{1}+\beta_{2} x_{2}+\cdots+\beta_{n} x_{n}
\end{gathered}
$$

Where; $\beta_{0}, \beta_{1}, \beta_{2}, \ldots \beta_{n}$ are constant parameters to be estimated. The logit model is therefore used to estimate the constant parameters by maximum likelihood estimation method.

The logit and Poisson models were combined to generate the zero-inflated regression model.

In this study, fertility was obtained from information provided by women of reproductive age on their full birth history. It is a count data and many women reported that they had no children. The data exhibited over-dispersion and excess zeros because the variance is much greater than the mean and the data is heavily skewed (Appendix 1). Also, the conventional Poisson regression model fits the data poorly, based on the deviance or Pearson Chi-square test, simply because the model assumption is based on the equality of the conditional variance and conditional mean of the dependent variable. In the used dataset, the conditional variance is greater than the conditional mean. Thus, over-dispersion was evident in the data. Therefore, in order to address this great limitation in the data, the ZIP 
regression was used. The ZIP model was designed to deal with situations where there is an "excessive" number of individuals with a count of 0 . The ZIP model allows for over-dispersion and the model assumes that the sample is a "mixture" of two sorts of individuals: one group whose counts are generated by the standard Poisson regression model, and another group (the absolute zero group) who have zero probability of a count greater than 0 . However, observed values of 0 could emerge from either of the two groups (Cameron and Trivedi, 2013; Hilbe and Greene, 2007).

The ZIP distribution combines the Poisson distribution and the logit distribution. In this distribution, the random variable $v_{i} \geq 0$. Assuming that two possible cases (case 1 or case 2) exist for each observation and suppose the count is zero if case 1 occurs. Conversely, for the occurrence of case 2, counts (including zeros) are created in line with a Poisson model. If $\omega$ is the probability that case 1 occurs, then its complement $(1-\omega)$ is the probability that case 2 occurs (Cameron and Trivedi, 2013; Hilbe, 2014; NCSS Statistical Software). Consequently, ZIP random variable $v_{i}$ has the probability distribution often expressed as;

$$
P\left(v_{i}=m\right)=\omega_{i}+\left(1-\omega_{i}\right) e^{\left(-\xi_{i}\right)} \text { if } m=0 \text { or } P\left(v_{i}=m\right)=\left(1-\omega_{i}\right) \frac{\xi_{i}^{v_{i}} e^{\left(-\xi_{i}\right)}}{v_{i} !} \text { if } m>0
$$

$\omega_{i}$ is the logistic link function defined as; $\omega_{i}=\lambda_{i} /\left(1+\lambda_{i}\right)$

Where

$$
\lambda_{i}=e^{\left\{l n\left(t_{i}\right)+\gamma_{1} z_{1 i}+\gamma_{2} z_{2 i}+\cdots+\gamma_{l} z_{l i}\right\}}
$$

The logistic component contains an exposure time $t$ and a set of $l$ regressor variables (the $z$ 's). If $t$ is the exposure time as defined by the Poisson component given a set of $k$ variables (the $x$ 's) such as; age at first marriage, sex preference, ethnicity, religion, household wealth, place of residence, region, education, ever used of modern contraceptive method, fertility preference, marital status and age at first birth. The expression connecting the independent and dependent variables is represented as;

$$
\xi_{i}=e^{\left\{l n\left(t_{i}\right)+\phi_{1} x_{1 i}+\phi_{2} x_{2 i}+\cdots+\phi_{k} x_{k i}\right\}}
$$

The regression coefficients $\phi_{1}, \phi_{2}, \ldots, \phi_{k}$ are the unknown parameters to be estimated from the analyzed data using the maximum likelihood estimation (MLE) method. The estimation procedures are expressed mathematically as shown below;

The logarithm of the likelihood function $(\log L)$ is the sum of $\log l_{1}$ and $\log l_{2}$ and a difference of $\log l_{3}$ where

$$
\begin{gathered}
\log l_{1}=\sum_{\left(i ; v_{i}=0\right)} \ln \left[\lambda_{i}+e^{\left(-\xi_{i}\right)}\right] \\
\log l_{2}=\sum_{\left(i ; v_{i}>0\right)}\left\{v_{i} \ln \left(\xi_{i}\right)-\xi_{i}-\ln \left(v_{i} !\right)\right\} \\
\log l_{3}=\sum_{i=1}^{n} \ln \left(1+\lambda_{i}\right)
\end{gathered}
$$

The gradient of $\mathcal{L}$ is

$$
\begin{array}{cc}
\frac{\partial \log L}{\partial \phi_{\tau}}=\sum_{\left(i ; v_{i}=0\right)}\left[\frac{-x_{i \tau} \xi_{i}}{\lambda_{i} e^{\left(\xi_{i}\right)}+1}\right]+\sum_{\left(i ; v_{i}>0\right)}\left[v_{i}-\xi_{i}\right] x_{i \tau,} \quad \tau=1,2, \ldots, k \\
\frac{\partial \log L}{\partial \psi_{\tau}}=\sum_{\left(i ; v_{i}=0\right)}\left[\frac{z_{i \tau} \lambda_{i} e^{\left(\xi_{i}\right)}}{\lambda_{i} e^{\left(\xi_{i}\right)}+1}\right]-\sum_{i=1}^{n}\left[\frac{\lambda_{i}}{1+\lambda_{i}}\right] z_{i \tau,} \quad{ }_{\tau=1,2, \ldots, l}
\end{array}
$$

The second derivatives are

$$
\frac{\partial^{2} \log L}{\partial \phi_{\tau} \partial \phi_{s}}=\sum_{\left(i ; v_{i}=0\right)}\left[\frac{x_{i \tau} x_{i s} \xi_{i}\left[\left(\xi_{i}-1\right) \lambda_{i} e^{\left(\xi_{i}\right)}-1\right]}{\left(\lambda_{i} e^{\left(\xi_{i}\right)}+1\right)^{2}}\right]-\sum_{\left(i ; v_{i}>0\right)} \xi_{i} x_{i \tau} x_{i s}, \quad \tau, s=1,2, \ldots, k
$$




$$
\begin{gathered}
\frac{\partial^{2} \log L}{\partial \psi_{\tau} \partial \psi_{s}}=\sum_{\left(i ; v_{i}=0\right)}\left[\frac{z_{i \tau} z_{i s} \lambda_{i} e^{\left(\xi_{i}\right)}}{\left(\lambda_{i} e^{\left(\xi_{i}\right)}+1\right)^{2}}\right]-\sum_{i=1}^{n} \frac{z_{i \tau} z_{i s} \lambda_{i}}{\left(\lambda_{i}+1\right)^{2}}, \quad \tau, s=1,2, \ldots, l \\
\frac{\partial^{2} \log L}{\partial \phi_{\tau} \partial \psi_{s}}=\sum_{\left(i ; v_{i}=0\right)}\left[\frac{x_{i \tau} z_{i s} \lambda_{i} \xi_{i} e^{\left(\xi_{i}\right)}}{\left(\lambda_{i} e^{\left(\xi_{i}\right)}+1\right)^{2}}\right] \tau=1,2, \ldots, k ; s=1,2, \ldots, l
\end{gathered}
$$

The solution to the partial differential equations above can be used to obtain the estimate of the parameters $\phi$ and $\psi$;

\section{Ethical Approval}

The use of data was permitted by the data originator, Micro International U.S.A. Informed consent was sought and granted by all the study participants during the data collection exercise. Those who did not want to partake in the study were not interviewed and each consenting participants was assured of anonymity and confidentiality of the information they provided.

\section{Results}

Figures 2(a-c) show the probability of bearing exact number of children by sex preference, ethnicity and religion. The data as shown in figure 2 a reveal that women who have sex preference have higher probability of bearing 1 to 2 children but lower probability of bearing at least 4 children than their counterparts who said they don't have preference for child's sex. For both groups of women, childbearing probability (ì) increases consistently from parity 0 to 2 but reduces thereafter and rises after bearing the fourth child. Probability of bearing at least 5 children was higher among women who do not have sex preference $(\grave{\eta}=0.2503)$ than those who have preference $(\grave{\eta}=0.1477)$. In figure $2 b$, there was no distinct pattern (dome shape) in childbearing probability among the Igbo and Yoruba ethnic group but completely different from the Hausa/Fulani's pattern. Among the Yoruba and Igbo, the probability rises until women in these ethnic groups bear their second child but falls consistently thereafter, unlike that of Hausa/Fulani women which rises from first birth to third and maintain a constant pattern till the fourth birth but rises again after bearing the fourth child. Probability of bearing at least 5 children was higher among the Hausa/Fulani women $(\grave{\eta}=0.3555)$ than Igbo $(\grave{\eta}=$

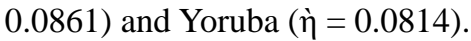

The childbearing probability reaches its peak at parity two for the Christians and falls consistently for higher parities. Childbearing probability for parities 0,1 and 2 was lower among the Muslims than Christians but reverse pattern was observed for parities 4 and above. For example, while the probability of bearing at least 5 children was $\grave{\eta}=0.3128$ among Muslim women, it was $\grave{\eta}=0.0803$ among the Christian women (Figure 2c). The interaction of all the three cultural factors specifically chosen for this study (sex preference, religion and ethnicity) regarding childbearing probability is shown in Figure 3. The data depict that the probability of bearing at least 5 children was highest among women who have no sex preference, belong to Muslim religious denomination, and of Hausa/Fulani ethnic group ( $\dot{\eta}=$ 0.3848). The next to these women in probability of bearing at least 5 children were those who have sex preference, belong to Muslim religious denomination, and of Hausa/Fulani ethnic group $(\grave{\eta}=0.2859)$. 


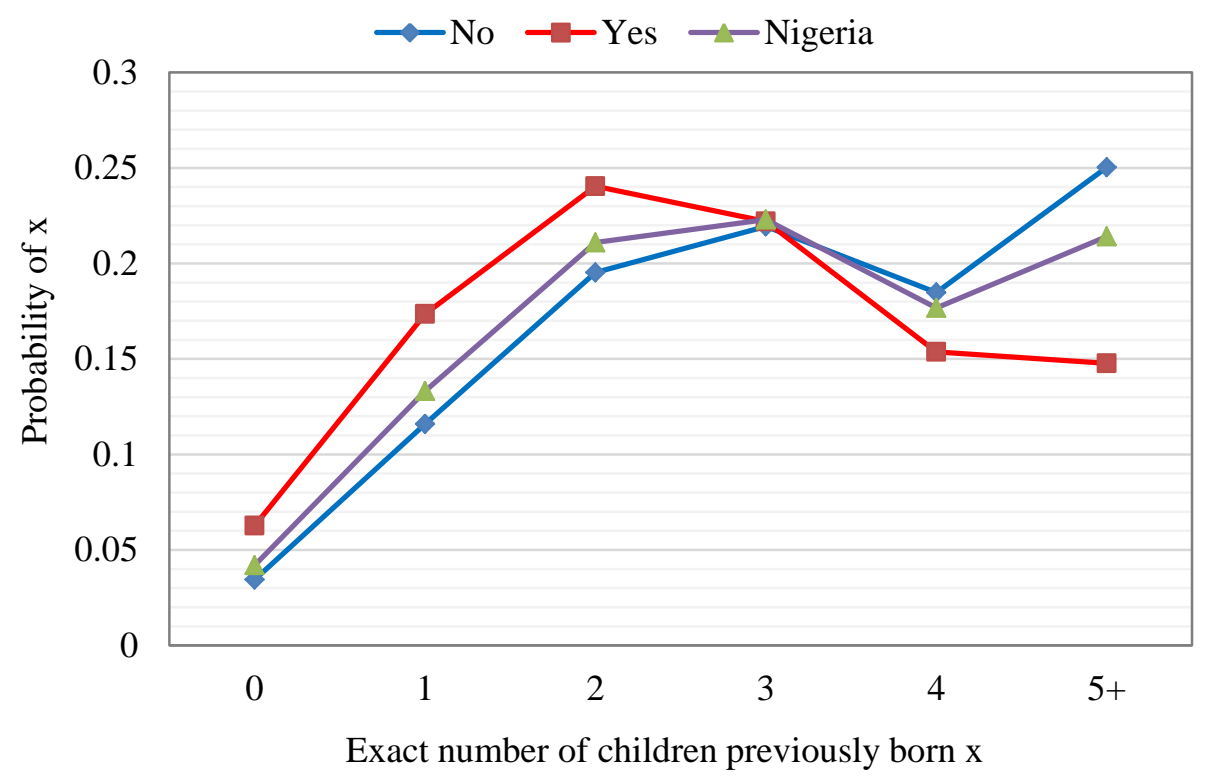

Figure 2a. Probability of exact number of children ever born according to sex preference

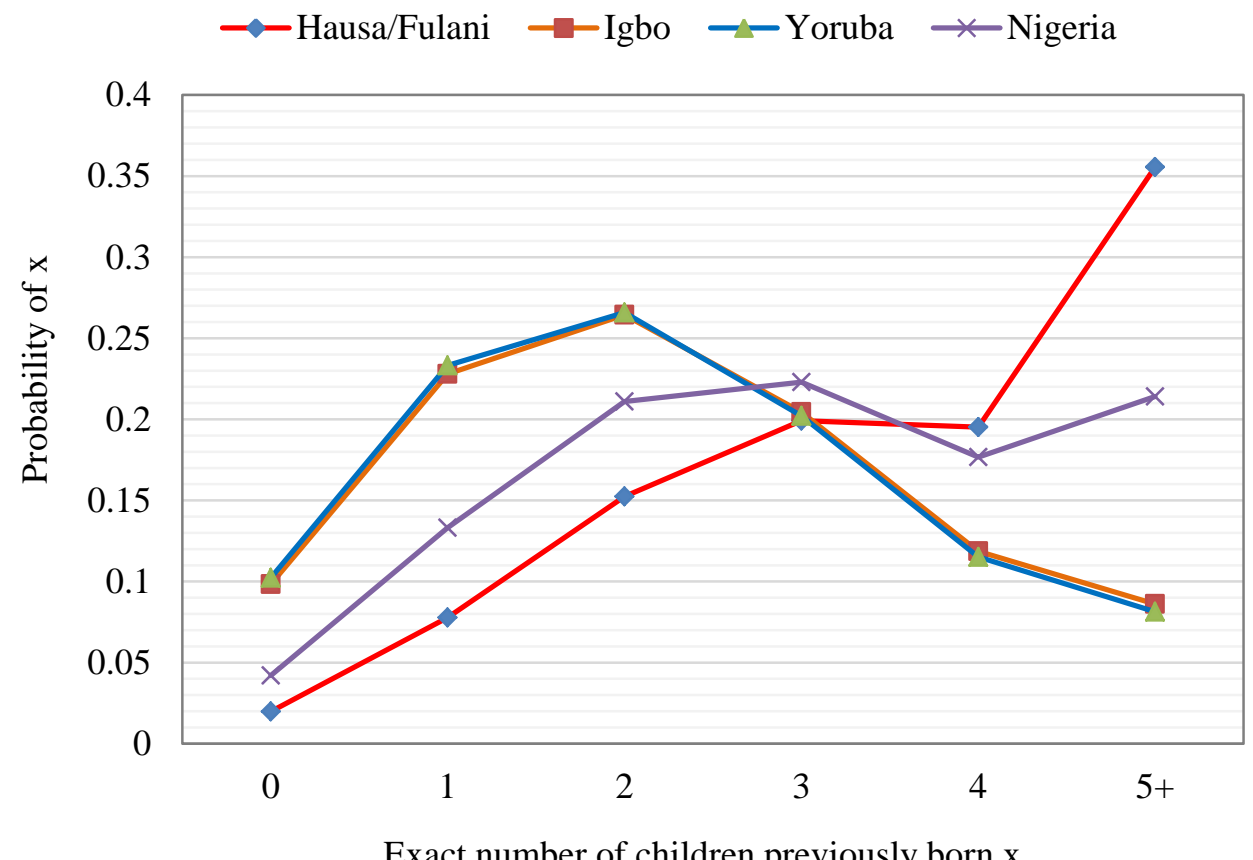

Figure 2b. Probability of exact number of children ever born according to ethnicity 


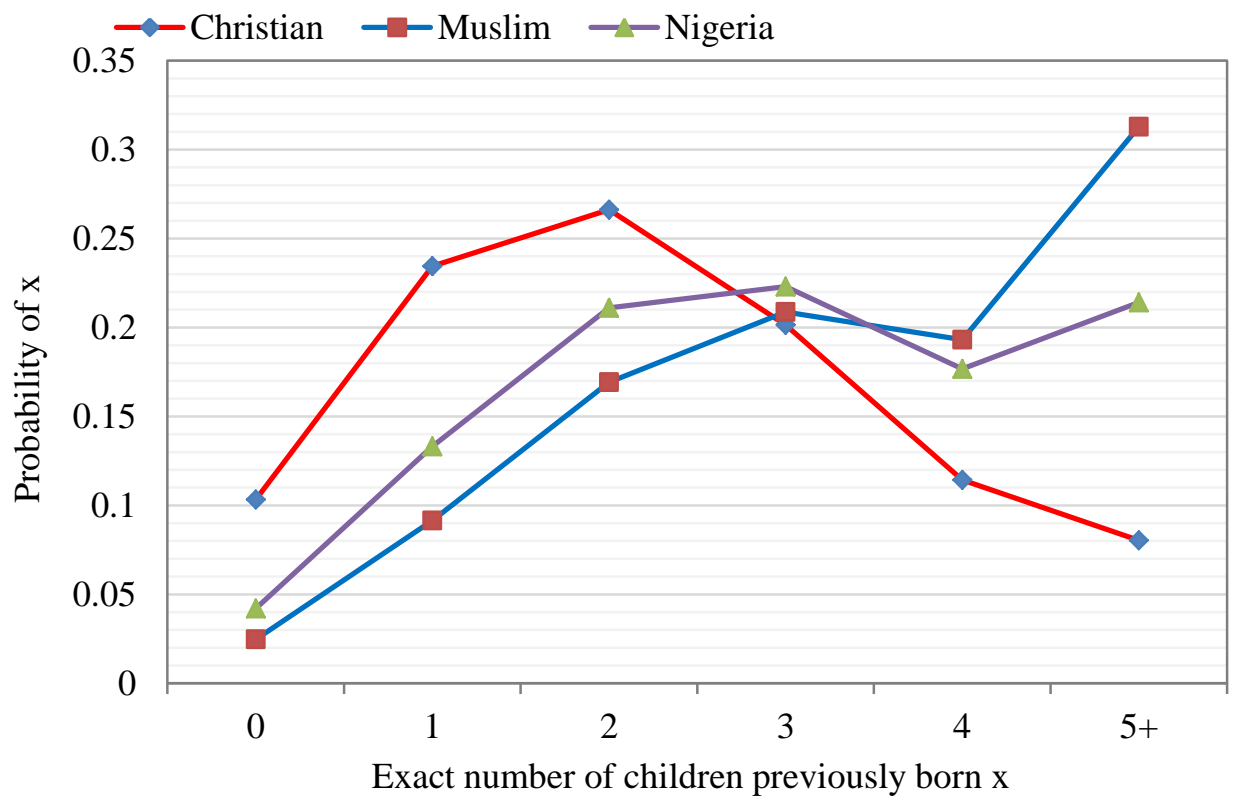

Figure 2c. Probability of exact number of children ever born according to religion

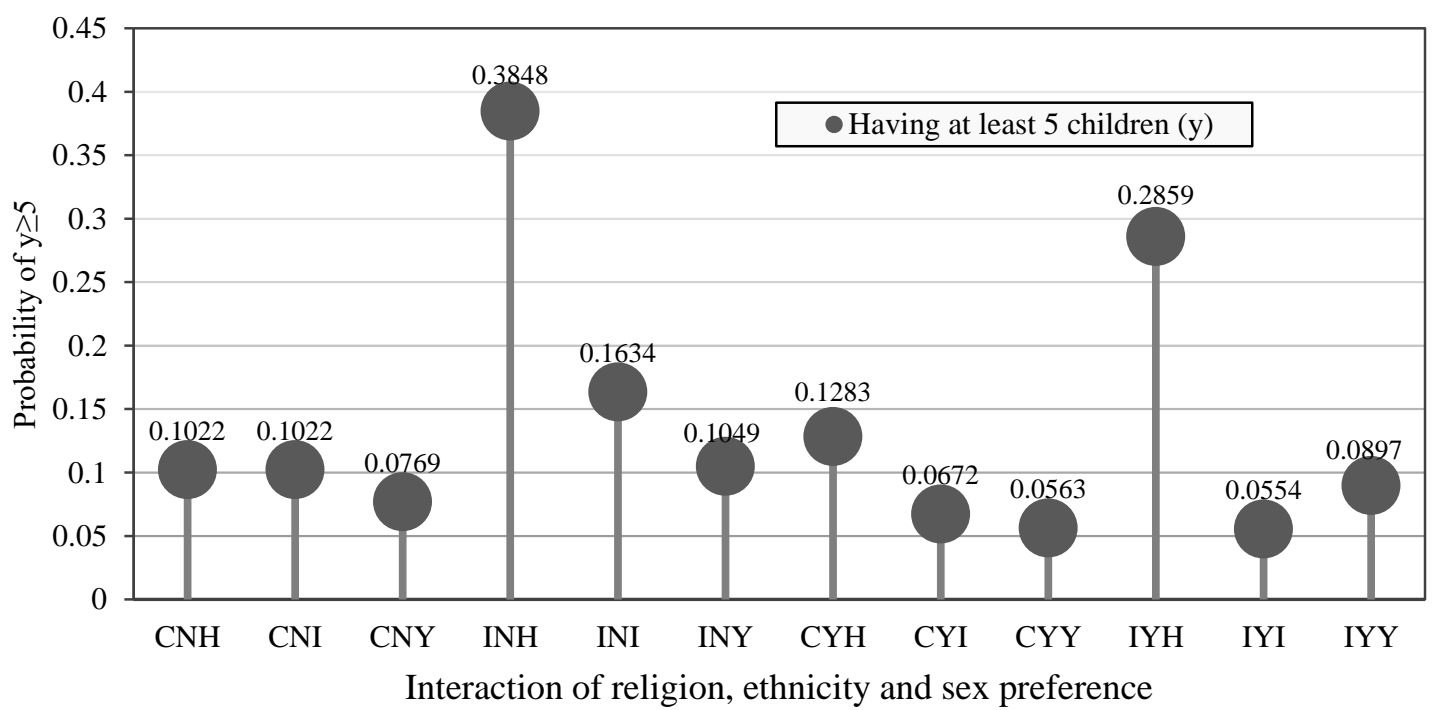

Figure 3. Probability of previously given birth to at least 5 children by cultural variables interactions

The computations of refined Total Fertility Rate (TFR) of the categories in the three cultural factors used in this study are as shown in Table 1. The data show that the refined TFR was higher among women who do not have sex preference (6.5) compared to those who have sex preference (5.8). Also, the TFR was lower among Christians (4.6) than Muslim women (7.8). The Hausa/Fulani ethnic group has the highest TFR (8.4) compared to Igbo (4.4) and Yoruba (4.9). In all the three major ethnic groups in Nigeria combined, the refined TFR was (6.3). 
Table 1. The Unrefined and Refined Total Fertility Rate by Cultural Characteristics and Nigeria

\begin{tabular}{|c|c|c|c|c|c|c|c|c|}
\hline Age & $P_{i}$ & $f_{i}$ & $\varphi_{i}$ & $F_{i}$ & $\omega_{i}$ & $f_{i}^{+}$ & $P_{i} / F_{i}$ & $f_{i}^{*}$ \\
\hline \multicolumn{9}{|c|}{ No sex preference: $R T F R=6.5$} \\
\hline $15-19$ & 0.2 & 0.08 & 0.40 & 0.1701 & 0.1547 & 0.1187 & 1.1756 & 0.1395 \\
\hline $20-24$ & 1.23 & 0.25 & 1.65 & 1.1098 & 0.1564 & 0.2567 & 1.1083 & 0.2845 \\
\hline $25-29$ & 2.62 & 0.29 & 3.10 & 2.5160 & 0.2059 & 0.3002 & 1.0413 & 0.3126 \\
\hline $30-34$ & 4.02 & 0.27 & 4.45 & 3.9401 & 0.2059 & 0.2535 & 1.0203 & 0.2587 \\
\hline $35-39$ & 5.33 & 0.19 & 5.40 & 5.0458 & 0.2447 & 0.1753 & 1.0563 & 0.1852 \\
\hline $40-44$ & 5.92 & 0.10 & 5.90 & 5.6864 & 0.3493 & 0.0895 & 1.0411 & 0.0932 \\
\hline $45-49$ & 6.96 & 0.04 & 6.10 & 6.0525 & & 0.0260 & 1.1499 & 0.0299 \\
\hline \multicolumn{9}{|c|}{ Sex preference: $R T F R=5.8$} \\
\hline $15-19$ & 0.21 & 0.09 & 0.45 & 0.1951 & 0.1617 & 0.1304 & 1.0765 & 0.1404 \\
\hline $20-24$ & 1.09 & 0.25 & 1.70 & 1.1574 & 0.1587 & 0.2556 & 0.9418 & 0.2407 \\
\hline $25-29$ & 2.46 & 0.29 & 3.15 & 2.5701 & 0.2067 & 0.2977 & 0.9572 & 0.2850 \\
\hline $30-34$ & 3.72 & 0.26 & 4.45 & 3.9665 & 0.2023 & 0.2407 & 0.9379 & 0.2257 \\
\hline $35-39$ & 4.84 & 0.17 & 5.30 & 4.9677 & 0.2438 & 0.1624 & 0.9743 & 0.1583 \\
\hline $40-44$ & 5.63 & 0.11 & 5.85 & 5.6746 & 0.3455 & 0.0901 & 0.9921 & 0.0894 \\
\hline $45-49$ & 6.22 & 0.02 & 5.95 & 5.9257 & & 0.0131 & 1.0497 & 0.0137 \\
\hline \multicolumn{9}{|c|}{ Hausa/Fulani: $R T F R=8.4$} \\
\hline $15-19$ & 0.35 & 0.15 & 0.75 & 0.3388 & 0.1645 & 0.2026 & 1.0330 & 0.2093 \\
\hline $20-24$ & 1.76 & 0.32 & 2.35 & 1.6860 & 0.1499 & 0.3183 & 1.0439 & 0.3323 \\
\hline $25-29$ & 3.60 & 0.34 & 4.05 & 3.3636 & 0.1970 & 0.3560 & 1.0703 & 0.3810 \\
\hline $30-34$ & 5.24 & 0.34 & 5.75 & 5.1029 & 0.2035 & 0.3239 & 1.0269 & 0.3326 \\
\hline $35-39$ & 6.74 & 0.25 & 7.00 & 6.5199 & 0.2484 & 0.2364 & 1.0338 & 0.2444 \\
\hline $40-44$ & 7.28 & 0.15 & 7.75 & 7.4296 & 0.3601 & 0.1343 & 0.9799 & 0.1316 \\
\hline $45-49$ & 8.24 & 0.06 & 8.05 & 7.9790 & & 0.0384 & 1.0327 & 0.0396 \\
\hline \multicolumn{9}{|c|}{ Igbo: $R T F R=4.4$} \\
\hline $\overrightarrow{15-19}$ & 0.07 & 0.04 & 0.20 & 0.0790 & 0.1347 & 0.0643 & 0.8856 & 0.0569 \\
\hline $20-24$ & 0.60 & 0.18 & 1.10 & 0.6723 & 0.1607 & 0.1991 & 0.8925 & 0.1777 \\
\hline $25-29$ & 1.62 & 0.27 & 2.45 & 1.8951 & 0.2247 & 0.2828 & 0.8548 & 0.2417 \\
\hline $30-34$ & 2.93 & 0.25 & 3.70 & 3.2401 & 0.2139 & 0.2259 & 0.9043 & 0.2043 \\
\hline $35-39$ & 3.97 & 0.15 & 4.45 & 4.1772 & 0.2409 & 0.1348 & 0.9504 & 0.1281 \\
\hline $40-44$ & 4.87 & 0.07 & 4.80 & 4.6950 & 0.3270 & 0.0564 & 1.0373 & 0.0585 \\
\hline $45-49$ & 6.08 & 0.01 & 4.85 & 4.8375 & & 0.0067 & 1.2569 & 0.0085 \\
\hline \multicolumn{9}{|c|}{ Yoruba: $R T F R=4.9$} \\
\hline$\overline{15-19}$ & 0.05 & 0.02 & 0.10 & 0.0284 & 0.1253 & 0.0426 & 1.7593 & 0.0749 \\
\hline $20-24$ & 0.62 & 0.18 & 1.00 & 0.5346 & 0.1710 & 0.2122 & 1.1598 & 0.2461 \\
\hline $25-29$ & 1.83 & 0.32 & 2.60 & 1.9646 & 0.2348 & 0.3216 & 0.9315 & 0.2996 \\
\hline $30-34$ & 2.94 & 0.24 & 3.80 & 3.3613 & 0.2092 & 0.2129 & 0.8747 & 0.1863 \\
\hline $35-39$ & 3.90 & 0.14 & 4.50 & 4.2497 & 0.2337 & 0.1247 & 0.9177 & 0.1145 \\
\hline $40-44$ & 4.50 & 0.06 & 4.80 & 4.7064 & 0.3199 & 0.0492 & 0.9561 & 0.0470 \\
\hline $45-49$ & 4.87 & 0.01 & 4.85 & 4.8375 & & 0.0068 & 1.0067 & 0.0068 \\
\hline \multicolumn{9}{|c|}{ Christian: $R T F R=4.6$} \\
\hline $15-19$ & 0.10 & 0.05 & 0.25 & 0.1005 & 0.1501 & 0.0800 & 0.9953 & 0.0796 \\
\hline $20-24$ & 0.76 & 0.20 & 1.25 & 0.8030 & 0.1617 & 0.2104 & 0.9465 & 0.1991 \\
\hline $25-29$ & 1.80 & 0.25 & 2.50 & 1.9916 & 0.2159 & 0.2592 & 0.9038 & 0.2343 \\
\hline $30-34$ & 3.07 & 0.23 & 3.65 & 3.2211 & 0.2102 & 0.2119 & 0.9531 & 0.2019 \\
\hline $35-39$ & 4.20 & 0.15 & 4.40 & 4.1272 & 0.2417 & 0.1354 & 1.0176 & 0.1378 \\
\hline $40-44$ & 5.04 & 0.07 & 4.75 & 4.6451 & 0.3276 & 0.0564 & 1.0850 & 0.0611 \\
\hline $45-49$ & 5.71 & 0.01 & 4.80 & 4.7875 & & 0.0067 & 1.1927 & 0.0080 \\
\hline \multicolumn{9}{|c|}{ Muslim: $R T F R=7.8$} \\
\hline $15-19$ & 0.31 & 0.12 & 0.60 & 0.2647 & 0.1635 & 0.1690 & 1.1710 & 0.1980 \\
\hline $20-24$ & 1.60 & 0.30 & 2.10 & 1.4717 & 0.1534 & 0.3001 & 1.0871 & 0.3262 \\
\hline $25-29$ & 3.29 & 0.32 & 3.70 & 3.0618 & 0.1982 & 0.3304 & 1.0745 & 0.3550 \\
\hline $30-34$ & 4.79 & 0.30 & 5.20 & 4.6298 & 0.2017 & 0.2849 & 1.0346 & 0.2948 \\
\hline $35-39$ & 6.24 & 0.22 & 6.30 & 5.8715 & 0.2484 & 0.2104 & 1.0628 & 0.2236 \\
\hline $40-44$ & 6.72 & 0.14 & 7.00 & 6.7159 & 0.3605 & 0.1233 & 1.0006 & 0.1233 \\
\hline $45-49$ & 7.61 & 0.05 & 7.25 & 7.1908 & & 0.0320 & 1.0583 & 0.0338 \\
\hline
\end{tabular}

RTFR: Refined Total Fertility Rate

In Table 2, the data show that $32.9 \%$ of the studied women have sex preference, $35.0 \%$ are Christians and $65.0 \%$ are Muslims. About 23\% of the women are Igbo, 21.5\% are Yoruba and 56.5\% belong to Hausa/Fulani ethnic group. The mean children ever born was 3.16 \pm 3.1 and was higher among women who had no sex preference (3.36 \pm 3.2 ). Approximately, $35.4 \%$ of the respondents had previously given birth to at least five children while $25.0 \%$ had $1-2$ 
children. Christian women (2.26 \pm 2.6$)$ had given birth to lower number of children than the Muslims (3.69 \pm 3.2$)$ and the percentage of Christian women who had at least five children was 24.1 compared to $41.5 \%$ observed among the Muslim women. The mean children ever born was lower among Yoruba (2.28 \pm 2.2$)$ than Igbo $(2.31 \pm 2.7)$ and Hausa/Fulani (3.91 \pm 3.4$)$ ethnic groups. About $44.3 \%$ of the women who are Hausa/Fulani had given birth previously to at least 5 children, compared to $26.1 \%$ and $21.6 \%$ observed for women in Igbo and Yoruba ethnic group respectively.

The percentage of women who married at ages $<18$ years $(47.2 \%)$, who are of parity of more than four children was higher than women who began their childbearing at ages $\geq 18$ years $(26.2 \%)$ and this pattern was observed in their mean children ever born. The percentage of women who had at least five children falls consistently with increasing wealth index and increasing level of education but was significantly higher among rural (41.0\%) than urban (28.8\%) women. High parity women ( $\geq 5$ children) was mostly found among women residence in the North West $(44.7 \%)$ and the least was found in the South West $(21.3 \%)$. However, the highest mean children ever born was found in the North West (3.98 \pm 3.4$)$ and the least in the South South $(1.87 \pm 2.2)$. Fertility preference was found to be significantly associated with children ever born and striking difference exists between women who had preference for less than five children (11.0\%) and those with preference for at least five children (43.5\%) in terms high parity.

Table 2. Distribution of the respondents by children ever born according to background characteristics

\begin{tabular}{|c|c|c|c|c|c|c|c|c|}
\hline \multirow{2}{*}{$\begin{array}{l}\text { Background } \\
\text { Characteristics }\end{array}$} & \multicolumn{4}{|c|}{ Children Ever Born } & \multirow{2}{*}{$\begin{array}{c}\text { Total } \\
\text { women }\end{array}$} & \multirow{2}{*}{$\begin{array}{l}\chi^{2} \text {-value } \\
(p \text {-value })\end{array}$} & \multirow{2}{*}{$\begin{array}{l}\text { Mean } \\
\text { CEB } \pm \sigma\end{array}$} & \multirow{2}{*}{$\begin{array}{l}\text { F-value } \\
\text { (p-value })\end{array}$} \\
\hline & None & $1-2$ & $3-4$ & $5+$ & & & & \\
\hline Total & 16.2 & 25.0 & 23.4 & 35.4 & 19348 & \multirow{4}{*}{$145.5^{* * *}$} & $3.16 \pm 3.1$ & \\
\hline \multicolumn{6}{|l|}{ Sex Preference } & & & \multirow[t]{3}{*}{$185.1^{* * *}$} \\
\hline No & 14.4 & 24.5 & 23.3 & 37.7 & 12985 & & $3.36 \pm 3.2$ & \\
\hline Yes & 19.9 & 25.9 & 23.6 & 30.6 & 6363 & & $2.77 \pm 2.9$ & \\
\hline \multicolumn{6}{|l|}{$\underline{\text { Religion }}$} & \multirow[t]{2}{*}{$861.5^{* * *}$} & & \multirow[t]{2}{*}{$1189.3 * * *$} \\
\hline Christian & 24.8 & 26.4 & 24.6 & 24.1 & 6775 & & $2.26 \pm 2.6$ & \\
\hline Muslim & 11.6 & 24.2 & 22.7 & 41.5 & 12574 & \multirow{5}{*}{$1268.5^{* * *}$} & $3.69 \pm 3.2$ & \multirow{5}{*}{$825.5 * * *$} \\
\hline \multicolumn{6}{|l|}{ Ethnicity } & & & \\
\hline Hausa/F & 11.1 & 23.3 & 21.2 & 44.3 & 10834 & & $3.91 \pm 3.4$ & \\
\hline Igbo & 27.5 & 24.8 & 21.3 & 26.4 & 4351 & & $2.31 \pm 2.7$ & \\
\hline Yoruba & 17.8 & 29.5 & 31.1 & 21.6 & 4162 & & $2.28 \pm 2.2$ & \\
\hline \multicolumn{6}{|l|}{ Age at first marriage } & \multirow[t]{4}{*}{$8317.0^{* * *}$} & & \multirow[t]{4}{*}{$5518.4 * * *$} \\
\hline Never in union & 87.7 & 11.5 & 0.6 & 0.2 & 1782 & & $0.05 \pm 0.3$ & \\
\hline$<18$ & 8.8 & 21.5 & 22.5 & 47.2 & 10617 & & $4.58 \pm 3.2$ & \\
\hline $18+$ & 9.3 & 33.7 & 30.6 & 26.4 & 6950 & & $3.27 \pm 2.4$ & \\
\hline \multicolumn{6}{|l|}{ Wealth index } & \multirow[t]{4}{*}{$897.8 * * *$} & & \multirow[t]{4}{*}{$870.2 * * *$} \\
\hline Poor & 11.3 & 22.5 & 21.0 & 45.1 & 8363 & & $4.11 \pm 3.4$ & \\
\hline Middle & 16.7 & 23.8 & 20.4 & 39.1 & 2875 & & $3.14 \pm 3.2$ & \\
\hline Rich & 21.2 & 27.9 & 26.9 & 24.0 & 8108 & & $2.32 \pm 2.5$ & \\
\hline Place of Residence & & & & & & $366.2 * * *$ & & $907.4 * * *$ \\
\hline $\begin{array}{l}\text { Urban } \\
\text { Rural }\end{array}$ & 19.9 & 26.4 & 24.9 & 28.8 & 8894 & & $2.55 \pm 2.8$ & \\
\hline $\begin{array}{c}\text { Rural } \\
\text { Region }\end{array}$ & 13.1 & 23.8 & 22.1 & 41.0 & 10455 & & $3.16 \pm 3.2$ & \\
\hline$\frac{\text { Region }}{\text { North Central }}$ & 19.1 & 28.4 & 26.1 & 26.4 & 800 & $1254.9 * * *$ & $2.30 \pm 2.3$ & $329.5^{* * *}$ \\
\hline North East & 13.0 & 26.3 & 20.2 & 40.6 & 1592 & & $3.57 \pm 3.2$ & \\
\hline North West & 11.1 & 22.7 & 21.5 & 44.7 & 9001 & & $3.98 \pm 3.4$ & \\
\hline South East & 27.6 & 23.1 & 19.5 & 29.7 & 3389 & & $2.41 \pm 2.9$ & \\
\hline South South & 27.8 & 30.1 & 24.2 & 17.9 & 442 & & $1.87 \pm 2.2$ & \\
\hline South West & 17.6 & 29.8 & 31.3 & 21.3 & 4124 & & $2.32 \pm 2.2$ & \\
\hline Education & & & & & & $2496.8 * * *$ & & $1634.9 * * *$ \\
\hline None & 10.0 & 21.3 & 21.5 & 47.2 & 9161 & & $4.41 \pm 3.3$ & \\
\hline Primary & 8.1 & 19.9 & 26.6 & 45.4 & 2973 & & $3.96 \pm 2.9$ & \\
\hline Secondary & 24.3 & 32.0 & 25.1 & 18.6 & 533 & & $1.71 \pm 2.2$ & \\
\hline Higher & 36.5 & 31.0 & 22.8 & 9.7 & 1884 & & $1.59 \pm 1.9$ & \\
\hline Ever used any contrac & ptive m & & & & & $415.3 * * *$ & & $13.9^{* * *}$ \\
\hline Yes & 14.4 & 25.6 & 21.2 & 38.7 & 14342 & & $3.20 \pm 3.2$ & \\
\hline No & 21.5 & 23.1 & 29.6 & 25.8 & 5007 & & $3.02 \pm 2.5$ & \\
\hline Fertility preference & & & & & & $1877.0 * * *$ & & $2559.0 * * *$ \\
\hline$<5$ & 27.6 & 34.9 & 26.6 & 11.0 & 4834 & & $1.60 \pm 2.0$ & \\
\hline $5+$ & 12.5 & 21.7 & 22.3 & 43.5 & 14514 & & $3.78 \pm 3.2$ & \\
\hline$\underline{\text { Marital Status }}$ & & & & & & $7436.9 * * *$ & & $9458.1 * * *$ \\
\hline Never Married & 87.7 & 11.5 & 0.6 & 0.2 & 1782 & & $0.05 \pm 0.3$ & \\
\hline Ever Married & 9.0 & 26.3 & 25.7 & 39.0 & 17566 & & $4.06 \pm 2.9$ & \\
\hline$\underline{\text { Age at first birth }}$ & & & & & & $772.5^{* * *}$ & & $1058.8^{* * *}$ \\
\hline$<18$ & N.A & 21.3 & 23.6 & 55.1 & 6573 & & $5.26 \pm 3.1$ & \\
\hline $18+$ & N.A & 35.6 & 30.9 & 33.5 & 9632 & & $3.85 \pm 2.5$ & \\
\hline
\end{tabular}

N.A: Not Applicable; ***p<0.001 
The data in Table 3 show the ZIP regression output of the relationship between fertility and sociocultural characteristics. Four models were used to establish the relationship, the first is the bivariate analysis of each of the key independent variables (sex preference, religion and ethnicity) and fertility. The incident rate ratio (IRR) of fertility was 1.091 (95\% C.I=1.076-1.105, $\mathrm{p}<0.001)$ times higher among women with no sex preference than women who have sex preference. The childbearing rate was higher among Hausa/Fulani (IRR=1.470, 95\% C.I=1.440-1.501, p<0.001) times and Igbo (IRR $=1.171,95 \%$ C.I $=1.141-1.201, \mathrm{p}<0.001)$ than Yoruba. Fertility IRR was significantly lower among Christian $(\mathrm{IRR}=0.802,95 \%$ C.I $=0.791-0.811, \mathrm{p}<0.001)$ than Muslim women. Similar pattern to the output of the first model was observed in model 2 (interaction between religion, sex preference and ethnicity) and full model (interaction between religion, sex preference, ethnicity and all variables).

In the third model, while fertility was 1.22 times higher among the Hausa/Fulani women compared to Yoruba, the Igbo women had $11 \%$ higher fertility compared to Yoruba. Women who got married at childhood ( $<18$ years) had $22 \%$ higher fertility compared to those who married at ages above 18 years. Women in the North East, North West and South East, were 49\% (IRR=1.485; C.I=1.229-1.642, p<0.001), 33\% (IRR=1.336; C.I=1.282-1.693, p<0.001) and 16\% (IRR=1.162; C.I=1.098-1.229, $\mathrm{p}<0.001)$ respectively more likely to have higher fertility compared to women in the South West. Fertility IRR was found to reduce as the level of education increases. In the 5th model, compared to Christians who are Yoruba and who have SP (Christianity $\times$ Yoruba $\times$ Yes), fertility incident rate ratio (IRR) was 34\%(1.041-1.714), 18\%(1.112-1.253), 15\%(1.070-1.227), 9\%(1.030-1.162) and 7\%(1.010-1.142) significantly higher among Christianity $\times$ No $\times$ Hausa/Fulani, Christianity $\times$ No $\times$ Yoruba, Christianity $\times$ No $\times$ Igbo, Islam $\times$ Yes $\times$ Yoruba, Islam $\times$ No $\times$ Hausa/Fulani and Islam $\times$ No $\times$ Yoruba respectively.

Table 3. Zero-Inflated Poisson regression analysis of fertility according to background characteristics

\begin{tabular}{|c|c|c|c|c|c|}
\hline $\begin{array}{l}\text { Background } \\
\text { Characteristics }\end{array}$ & $\begin{array}{c}\text { Model } 1 \\
\text { uIRR }\end{array}$ & $\begin{array}{c}\text { Model } 2 \\
\text { aIRR }\end{array}$ & $\begin{array}{c}\text { Model } 3 \\
\text { aIRR }\end{array}$ & $\begin{array}{c}\text { Model } 4 \\
\text { uIRR } \\
\end{array}$ & $\begin{array}{c}\text { Model } 5 \\
\text { aIRR } \\
\end{array}$ \\
\hline \multicolumn{6}{|l|}{ Sex Preference } \\
\hline No & $\begin{array}{c}1.091 * \\
(1.076-1.105)\end{array}$ & $\begin{array}{c}1.081 * \\
(1.062-1.101)\end{array}$ & $\begin{array}{c}1.123^{*} \\
(1.102-1.141)\end{array}$ & & \\
\hline \multicolumn{6}{|l|}{ Interaction } \\
\hline \multicolumn{2}{|c|}{ Christianity $\times$ Yes $\times$ Hausa/Fulani } & & & $\begin{array}{c}1.120 \\
(0.951-1.312)\end{array}$ & $\begin{array}{c}1.071 * \\
(0.901-1.257)\end{array}$ \\
\hline \multicolumn{2}{|c|}{ Christianity $\times$ No $\times$ Hausa/Fulani } & & & $\begin{array}{c}1.221 \\
(0.952-1.563)\end{array}$ & $\begin{array}{c}1.340^{*} \\
(1.041-1.714)\end{array}$ \\
\hline \multicolumn{2}{|c|}{ Islam $\times$ No $\times$ Hausa/Fulani } & & & $\begin{array}{c}1.702 * * * \\
(1.631-1.803)\end{array}$ & $\begin{array}{c}1.081 * \\
(1.011-1.163)\end{array}$ \\
\hline \multicolumn{2}{|c|}{ Islam $\times$ Yes $\times$ Hausa/Fulani } & & & $\begin{array}{c}1.502 * * * \\
(1.433-1.581)\end{array}$ & $\begin{array}{c}0.971 \\
(0.912-1.044)\end{array}$ \\
\hline \multicolumn{2}{|c|}{ Christianity $\times$ No $\times$ Igbo } & & & $\begin{array}{c}1.051 \\
(0.990-1.109)\end{array}$ & $\begin{array}{c}1.152 * * * \\
(1.070-1.227)\end{array}$ \\
\hline \multicolumn{2}{|c|}{ Christianity $\times$ Yes $\times$ Igbo } & & & $\begin{array}{c}0.912 * * * \\
(0.860-0.958)\end{array}$ & $\begin{array}{c}0.990 \\
(0.921-1.057)\end{array}$ \\
\hline \multicolumn{2}{|c|}{ Islam $\times$ No $\times$ Igbo } & & & $\begin{array}{c}1.231 \\
(0.891-1.693)\end{array}$ & $\begin{array}{c}0.841 \\
(0.604-1.154)\end{array}$ \\
\hline \multicolumn{2}{|c|}{ Islam $\times$ Yes $\times$ Igbo } & & & $\begin{array}{c}0.921 \\
(0.512-1.671)\end{array}$ & $\begin{array}{c}0.633 \\
(0.340-1.142)\end{array}$ \\
\hline \multicolumn{2}{|c|}{ Christianity $\times$ No $\times \times$ Yoruba } & & & $\begin{array}{c}0.931 * * \\
(0.880-0.984)\end{array}$ & $\begin{array}{c}1.180 * * * \\
(1.112-1.253)\end{array}$ \\
\hline \multicolumn{2}{|c|}{ Islam $\times$ No $\times$ Yoruba } & & & $\begin{array}{c}0.871 * * * \\
(0.812-0.931)\end{array}$ & $\begin{array}{c}1.072 * \\
(1.001-1.142)\end{array}$ \\
\hline \multicolumn{2}{|c|}{ Islam $\times$ Yes $\times$ Yoruba } & & & $\begin{array}{c}1.051 \\
(0.981-1.113)\end{array}$ & $\begin{array}{c}1.092 * * \\
(1.030-1.162)\end{array}$ \\
\hline \multicolumn{6}{|c|}{ Age at first marriage } \\
\hline \multicolumn{2}{|c|}{ Never in union } & & $\begin{array}{c}0.021^{*} \\
(0.019-0.024)\end{array}$ & & $\begin{array}{c}0.022^{*} \\
(0.019-0.024)\end{array}$ \\
\hline$<18$ & & & $\begin{array}{c}1.218^{*} \\
(1.193-1.244)\end{array}$ & & $\begin{array}{c}1.218^{*} \\
(1.193-1.244)\end{array}$ \\
\hline
\end{tabular}




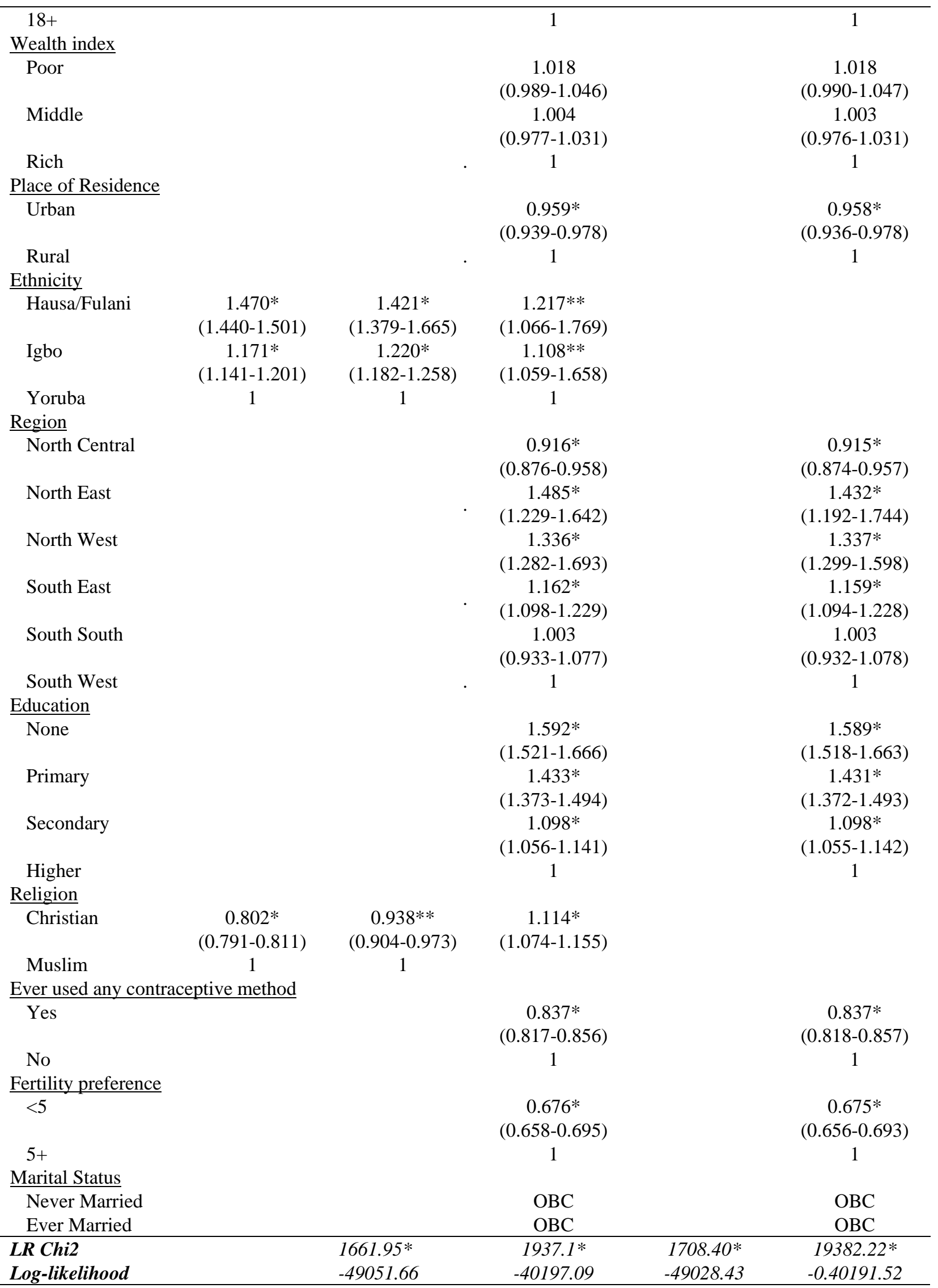

UIRR: Unadjusted Incidence Rate Ratio; aIRR: Adjusted Incidence Rate Ratio; CI: Confidence Interval; OBC: Omitted because of collinearity; ${ }^{*}<<0.05, * * p<0.01, * * * p<0.001$ 


\section{Discussion}

Fertility in relation to population growth remains a problem in Nigeria. Fertility rate reduction has always been an issue of important focus by the Nigeria Government and non-governmental agencies. Unfortunately, modern contraceptives which researchers have identified as an approach to fertility control is underutilized in Nigeria. Many factors including religion, ethnicity and sex preference have implication on the use of modern contraceptive in Nigeria and they can be linked to childbearing. The general influence of high population growth on the standard of living, limited resources will continue for years if necessary measures are not taken to check fertility. These effects are currently being witnessed in the area of environmental degradation, human congestion, air pollution and poverty. This paper examined the relationship between religion, sex preference, ethnicity and fertility against the presence of limited research evidence on such studies in Nigeria. The findings are expected to guide family planning programmers in their implementation of reproductive health programmes that will decrease fertility in the country in the nearest future.

In 1988, the Nigerian government published its first population policy in response to the rising population growth rate which has tendencies to impede developmental efforts in the country (Federal Ministry of Health, 1988). Paramount among the target stipulated in the policy is the intention to reduce total fertility rate to 4, by the year 2000 . Unfortunately, above a decade after this target the TFR still remains at 5.5 (National Population Commission and ICF International, 2014). In the policy document, it was recommended that families should restrict the number of children they bear to 4 or less (Federal Ministry of Health, 1988). Our finding revealed that about one-third of the studied women had given birth to more than four children in Nigeria. It is most likely that this proportion increases if all the studied women were to be followed-up till the end of their reproductive periods. This finding is an indication that large family size still dominates some Nigerian families despite the recommendation that a family should not bear more than four children (Federal Ministry of Health, 1988). Reasons for high fertility could be linked to high childhood mortality in Nigeria and cultural practices that favor large family size which have been identified in the literature (National Population Commission and ICF International, 2013; Feyisetan and Bankole, 2002; Syamala, 2001).

Having sex preference is one of the sociocultural problems that exists in families in Nigeria (Adebowale et al., 2014). In both traditional and contemporary Nigeria's family, children have always been wanted. However, the number a woman bears depends on her physiological capacity to produce but modernization and harsh economic condition in Nigeria moderate the decision on family size. In this context, couple may wish to halt childbearing once the desired number has been achieved but this may be shifted if they are not satisfied with the sex composition of their living children or at times if the family is yet to have a child of opposite sex to the ones they already have. This situation has stimulated some families to bear more than their preferred number of children (Adebowale and Palamuleni, 2015; Ushie et al., 2013). Finding from our study shows that about one-third of the studied women had sex preference. However, it is striking that women who do not have sex preference had higher childbearing probability and total fertility rate than their counterparts who have preference. This pattern was also corroborated by the output of the multivariate analyses. Fertility desire at the onset of childbearing may not translate to the attained fertility (Milazzo, 2014). Obtaining information from women on sex preference is subjective as the current sex composition of the surviving children often dictates the tune of response to such question. The possible explanation for our finding is that, women who have completed their childbearing or already have their desired number of children may likely have no sex preference or respond based on the sex composition of the children they have. Conversely, the younger women who either have not completed their family size or bear no children may have preference for their anticipated child's gender.

The ethnic group a woman belongs can guide her attitudes to social phenomena including her practices of childbearing. Her ethnic identity can shape her cultural understanding and interpretation of demographic indices like fertility (Abbasi and Sadeghi, 2006; Kollehlon,1989). Among the three major ethnic groups in Nigeria, both probability of bearing more than four children, total fertility rate and incidence rate ratio of fertility were highest among the Hausa/Fulani women but slight disparities were found between Igbo and Yoruba women. This finding is consistent with previous similar studies where higher fertility indices were found among Hausa/Fulani than Igbo and Yoruba ethnic group (Mberu and Reed, 2014; Kollehlon,1989). The consistent reporting of higher fertility among Hausa/Fulani women can be linked with cultural differences and low literacy level compared to other ethnic groups in Nigeria (NPC, 2006). These in most situations have hindered Hausa/Fulani women from seeking fertility control measures like the use of modern contraceptive compared to Yoruba and Igbo women (National Population Commission and ICF International, 2013).

Religion is an authentic fulcrum of socialization in any society. It is an integrative social force that shapes collective belief into collective identity and it promotes group solidarity and cohesion (Okon, 2012). Identification with a particular religious group, gives the member a sense of belonging but non-members a feeling of disaffection and isolation (Okon, 2012). The religious affiliation of a woman has previously been established as one of the key determinants of fertility (Fagbamigbe and Adebowale, 2014; Akpa and Ikpotokin, 2012). In this study, the analysis targeted women who belong to either of the two major ethnic groups in Nigeria, Christianity and Islam. Across all the 
level of analyses used in this study, consistently, fertility and the likelihood of having previously given birth to at least five children were higher among the Muslims than the Christians. The same pattern holds true in some of the countries where Muslims live in large numbers alongside other religious groups. The outcomes from previous studies in Nigeria and other parts of the world corroborate this finding (Fagbamigbe and Adebowale, 2014; Akpa and Ikpotokin, 2012; Agadjanian and Yabiku, 2014; Westoff and Kristin, 2015). In the report of past Demographic and Health Survey conducted in Nigeria from 1990-2013, the median age; at first sex, first marriage and childbearing were consistently higher among the Muslims than Christians (National Population Commission and ICF International, 1990; 1999; 2003; 2008 ; 2013). All these demographic indicators have implication on childbearing and therefore, can explain the reason for our finding.

In the interactive model of sex preference, religion and ethnicity on their joint role on childbearing probabilities, the chance of bearing at least five children was highest among women who; have no sex preference, belong to Muslim religious denomination, and are of Hausa/Fulani ethnic background. Other factors that were found in this study as stimulant to high fertility in Nigeria were child marriage, being poor, living in rural areas, lower level of education and residing in North West and these have been extensively documented in literature (Fagbamigbe and Adebowale, 2014; Akpa and Ikpotokin, 2012; Mberu and Reed, 2014; Kollehlon,1989).

Despite the emerging important findings from this study. The readers should interpret the findings with caution due to cross-sectional design approach used. Therefore, the causality between fertility and the independent variables cannot be ascertained. Although, there is likelihood of misreporting of the number of children ever born which was the outcome variable for this study, the data originators ensured that such errors were minimized to bearable minimum during data collection.

\section{Conclusions}

Fertility is high among women included in this study. Religion, ethnicity and sex preference are among the determinants of fertility. Although, difference exists among religious, ethnic and sex preference groups. Programmes that aim to reduce fertility rates should focus on these factors. High fertility was facilitated by women who lack education, live in rural area, married early, Muslims and of Hausa/Fulani ethnic background. Residing in the region with Muslim majority positively influences fertility. Fertility reduction strategies should be intensified in Nigeria, but more attention must be given to Muslims and Hausa/Fulani women.

\section{Authors' contribution}

This work was carried out in collaboration between all authors. Adebowale SA conceived the idea, wrote introduction and contributed to methodology, results and discussion writing. Asa S reviewed relevant literatures, contributed to the data analysis and discussion. Abe JO was involved in writing the methodology, data analysis and results sections while author Oyinlola FF provided a draft of the discussion. All authors reviewed and approved the final manuscript.

\section{Competing Interests}

Authors have declared that no competing interests exist in the course of this study's conceptualization and implementation.

\section{Acknowledgement}

The authors would like to thank the National Population Commission and ICF Macro Calverton, Maryland, USA for releasing the data for this study.

\section{References}

Abbasi, S. M. J., \& Sadeghi, R. (2006). Ethnicity and fertility: an analysis of fertility behavior of ethnic groups in iran. Nameh-ye olum-e ejtemai, 29, 29-58.

Adebowale, A. S., Bidemi, Y. O., \& Palamuleni, E. M. (2014). Child's gender preference: is there regional difference among married women in stable Union in Nigeria. Gend Behav, 12(3), 5868-84.

Adebowale, S. A., \& Palamuleni, M. E. (2015). Influence of gender preference and sex composition of surviving children on childbearing intention among high fertility married women in stable union in Malawi. African health sciences, 15(1), 150-160. https://doi.org/10.4314/ahs.v15i1.21

Adhikari, R. (2010). Demographic, socio-economic, and cultural factors affecting fertility differentials in Nepal. BMC pregnancy and childbirth, 10(1), 19. https://doi.org/10.1186/1471-2393-10-19

Agadjanian, V., \& Yabiku, S. T. (2014). Religious affiliation and fertility in a sub-Saharan context: dynamic and lifetime perspectives. Population research and policy review, 33(5), 673-691. https://doi.org/10.1007/s11113-013-9317-2 
Agarwal, B. (1997). "Bargaining" and gender relations: Within and beyond the household. Feminist economics, 3(1), 1-51. https://doi.org/10.1080/135457097338799

Akpa, O. M., \& Ikpotokin, O. (2012). Modeling the determinants of fertility among women of childbearing age in Nigeria: Analysis using generalized linear modeling approach. Int J Humanit Soc Sci, 2(18), 167-176.

Alo, O. A. (2011). Fertility regimentation of the rural Yoruba women of South-west Nigeria: The case of Ido and Isinbode. Journal of Social Sciences, 26(1), 57-65. https://doi.org/10.1080/09718923.2011.11892882

Amoo, E. O. (2011). Trends and Proximate Determinants of Fertility Decline in Nigeria.

Cameron, A. C., \& Trivedi, P. K. (2013). Regression analysis of count data (Vol. 53). Cambridge university press.

Coale, A. J., \& Trussell, T. J. (1974). Model fertility schedules: variations in the age structure of childbearing in human populations. Population index, 185-258. https://doi.org/10.2307/2733910

Fagbamigbe, A. F., \& Adebowale, A. S. (2014). Current and predicted fertility using Poisson regression model: evidence from 2008 Nigerian demographic health survey. African journal of reproductive health, 18(1), 71-83.

Federal Ministry of Health. (1988). National Policy on Population for Development, Unity, Progress and Self-Reliance. Lagos, Nigeria: Department of Population Activities

Feyisetan, B. J., \& Bankole, A. (2002). Fertility transition in Nigeria: Trends and Prospects, http://www.Un.org/esa/population/PDF>, Accessed Aug. 06, 2016

Hilbe, J. M., \& Greene, W. H. (2007). Count response regression models, in (eds) C.R. Rao, J.P. Miller, and D.C. Rao, Epidemiology and Medical Statistics, Elsevier Handbook of Statistics Series, London: Elsevier. https://doi.org/10.1016/S0169-7161(07)27007-5

Kollehlon, K. T. (1989). Ethnicity and fertility in Liberia: a test of the minority group status hypothesis. Social biology, 36(1-2), 67-81. https://doi.org/10.1080/19485565.1989.9988720

Malthus, T. R. (1798). Essay on the Principle of Population, ed. A. Flew. Harmondsworth: Penguin, 1970.

Mberu, B. U., \& Reed, H. E. (2014). Understanding subgroup fertility differentials in Nigeria. Population review, 53(2), 23.

Milazzo, A. (2014). Son Preference, Fertility and Family Structure: Evidence from Reproductive Behavior among Nigerian Women. Policy Research Working Paper 6869.

National Population Commission and ICF International. (2013). Nigeria Demographic and Health Survey 2013. Abuja, Nigeria, and Rockville, Maryland, USA: NPC and ICF International.

National Population Commission. (1990). National policy on population for sustainable development. Abuja, Nigeria: National Population Commission.

National Population Commission. (1999). National policy on population for sustainable development. Abuja, Nigeria: National Population Commission.

National Population Commission. (2003). National policy on population for sustainable development. Abuja, Nigeria: National Population Commission.

National Population Commission. (2008). National policy on population for sustainable development. Abuja, Nigeria: National Population Commission.

NCSS Statistical Software. Zero-Inflated Poisson Regression. 329, 1-32. Retrieved from https://ncss-wpengine.netdna-ssl.com/wp-content/themes/ncss/pdf/Procedures/NCSS/Zero-Inflated_Poisson_Regre ssion.pdf

NPC. (2006). Nigeria population Census 2006. National Population Commission.

Okon, E. E. (2012). Religion as Instrument of Socialization and Social Control. European Scientific Journal November edition, 8(26), 136-142.

Population Reference Bureau. (2016). World population data sheet with a special focus on human needs and sustainable resources. worldpopdata.org.

Population Reference Bureau. (2018). World population data sheet with a special focus on changes in age structure. worldpopdata.org.

Schultz, T. P. (2005). Fertility and Income. Yale University-Economic Growth Center; Institute for the Study of Labor (IZA). Yale University Economic Growth Center Discussion Paper No. 925 
Syamala, T. S. (2001). Relationship between infant and child mortality and fertility-An enquiry into goan women. The Indian Journal of Pediatrics, 68(12), 1111-1115. https://doi.org/10.1007/BF02722920

The World Bank Development Research Group Human Development and Public Services Team May 2014. https://doi.org/10.1596/1813-9450-6869

Ushie, M. A., Enang, E. E., \& Ushie, C. A. (2013). Implications of sex preference for population growth and maternal health in obudu and obanliku, cross river state, Nigeria. Academic Research International, 4(3), 492.

Westoff, C. F., \& Kristin, B. (2015). Religion and Reproductive Behavior in Sub-Saharan Africa. DHS Analytical Studies No. 48. Rockville, Maryland, USA: ICF International.

Appendix 1: Distribution of number of births previously born alive among women of reproductive age in Nigeria

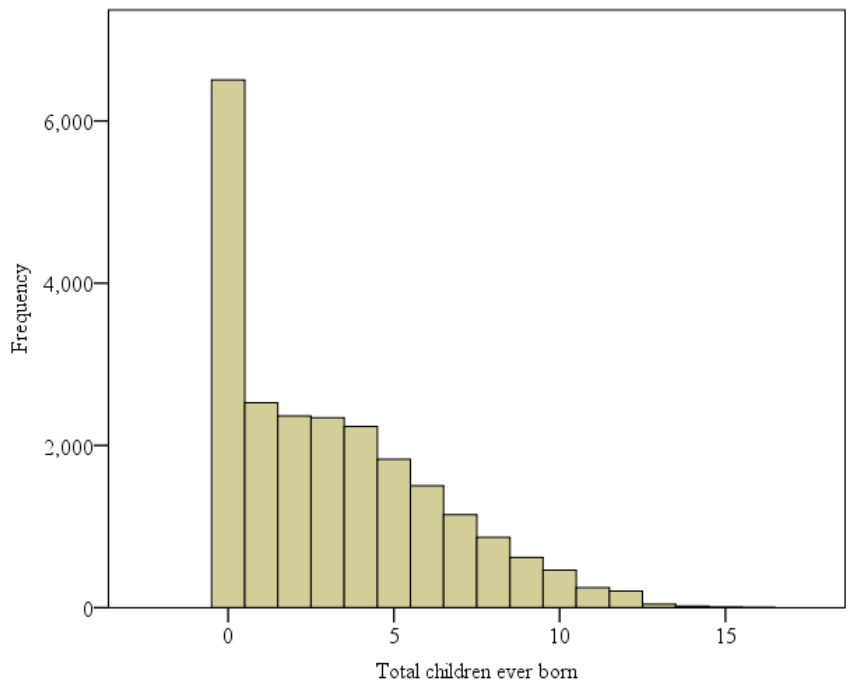

Mean $=3.17 ;$ Variance $=9.56$

\section{Copyrights}

Copyright for this article is retained by the author(s), with first publication rights granted to the journal.

This is an open-access article distributed under the terms and conditions of the Creative Commons Attribution license (http://creativecommons.org/licenses/by/4.0/). 